\title{
Contribution of Bilingualism in Language Teaching
}

\author{
Muhammad Aslam Sipra ${ }^{1}$ \\ ${ }^{1}$ JCC, King Abdulaziz University, Saudi Arabia \\ Correspondence: Dr. Muhammad Aslam Sipra, JCC, Department of GRC, King Abdulaziz University, PO Box \\ 80283, Jeddah 21589, Saudi Arabia. Tel: 966-2-2870026 Ext: 580. E-mail: Aslamsipra@yahoo.com
}

Received: September 26, 2012 Accepted: October 28, 2012 Online Published: December 12, 2012

doi:10.5539/elt.v6n1p56 URL: http://dx.doi.org/10.5539/elt.v6n1p56

\begin{abstract}
This study is an investigation into the contribution of the use of bilingualism as an aid in learning/teaching English as a foreign language and bilingualism in EFL classroom does not reduce students' communicative abilities but in effect can assist in teaching and learning process. The study employed a qualitative, interpretive research design involving questionnaires, classroom observations and semi-structured interviews. The data part analyzed the students and the teachers' expressed responses and beliefs about the role of bilingualism in EFL classes. The findings of the study in general are that bilingualism as a resource in teaching facilitates in learning L2 and helps make more people acknowledge the contribution of bilingualism in EFL classes.
\end{abstract}

Keywords: bilingualism, second language learning, mother tongue, L1, L2, language teaching

\section{Introduction}

In the fall of 2004, almost seven years hence, as I started teaching English language at intermediate level in Saudi Arabia, I was confronted by a problem of not being able to make my students understand quite a number of expressions in the target language sometimes; thus, finding the class difficult to manage. This problem owed to my almost zero ability in Arabic that is/was the L1 of my students. However, as the time went by I picked up a bit of Arabic vocabulary and quite a few of expressions and this newly acquired ability in Arabic enabled me to use bilingualism effectively in classes. I started using students' L1, as and when required, and I felt a tremendous change in students' results and their linguistic behaviour. This inspired me to conduct a research on the use of bilingualism in EFL classes. In the light of my experience in the classroom I wanted to fathom the usefulness of bilingualism as a teaching aid at intermediate level. And whether it really helps the students learning the target language with an ease?

There has been much debate and controversy over the use of bilingualism as a teaching aid and a resource in teaching EFL. In this study the researcher has attempted to investigate into the scope of the contribution of use of bilingualism in foreign language learning/teaching class. The study of bilingualism covers a field which is both wide and interdisciplinary. The article is mainly concerned with 'bilinguality' rather than 'bilingualism' because it is a study of EFL teachers' second language use in the classroom how they may impact on learning a second language. However, in as much as bilinguality develops and is manifested in situated social ways, there will be mention of societal aspects of bilingualism at points when it is necessary in interpreting the findings.

Bilingualism in the classroom is not considered as the medium of teaching as happens in grammar-translation method, but as a teaching technique or if I am allowed to say, as a teaching aid. Once let loose the bilingualism pervades the whole of classroom teaching; instead, it is used only of well-defined steps of teaching and in clearly defined manner. In using the mother tongue, the teacher in the grammar translation method has all the freedom of expressing himself in it and bilingualism in EFL classes strikes the middle and permits judicious freedom in the use of the first language.

\section{Literature Review}

This part of study seeks to give an overview of the existing literature available on the various aspects of bilingualism. Although not an extensive research has been conducted on this issue, yet the subject invites many different areas of TEFL, which have been sought by the scholars. Bilingualism can be discussed as an individual phenomenon or a societal phenomenon (Skutnabb-Kangas, 1981). Hamers and Blanc (2000) use the term "bilinguality" to denote an individual's use of two languages, and reserve "bilingualism" for the study of how two or more languages function in a given society. However, they do not suggest that it is possible to see each in 
isolation from the other, pointing out their interdependency. Bilingualism in education looks at the pedagogical issues when children speaking one language at home enter a school system which operates in another language (Lotherington 2000). There are numerous academic institutions all over the world which attempt to find the best way for children to become proficient in the dominant language (Cummins and Swain 1986). There are other studies available which look at how children growing up in bilingual families acquire both languages, and how parents can help them to retain both (Beligan, Clyne and Lotherington 1999). In another research, conducted by Jinlan Tang (2002) emphasized the idea that L1 in the English class helps the students to improve their L2 linguistic capabilities. He conducted his research on Chinese students and his results proved the idea of Schweer's study results. Schweers (1999) conducted a study with EFL students and their teachers in a Spanish context to investigate their attitudes toward using L1 in the L2 classroom. His results indicate that Spanish should be used in the EFL classroom.

Unfortunately, many people think that there is only room enough in a child's or adult's brain for one language. Contrary to the idea that two languages confuse people, there is evidence that well-developed bilingualism actually enhances one's "cognitive flexibility" -- that is, bilingual people including children are better able to see things from two or more perspectives and to understand how other people think (Hakuta 1986). Bilinguals also have better auditory language skills i.e., they can discriminate sounds of a language more finely than monolinguals, and they mature earlier than mono-linguals in terms of linguistic abstraction i.e., ability to think and talk about language (Albert \& Obler 1978). Simply being exposed to a language is no guarantee that we will learn it. If we are exposed to language input that we cannot understand, much of what is said (or written) will be "over our heads." In order for language learning to take place, we must receive "comprehensible input" -- that is, language input must be modified so that we can understand it (Krashen 1981). Furthermore, studies have shown that when minority students are provided with native language instruction for at least $50 \%$ of the day through grades 5 or 6 , they do better academically than those in all-English programs. In other words, they suffer no loss as a result of less exposure to English, and in fact by 6th or 7th grade they appear to be gaining on their counterparts in all-English programs (Collier 1995).

Children's mother tongues are fragile and easily lost in the early years of school. Many people marvel at how quickly bilingual children seem to pick up conversational skills in the majority language in the early years at school although it takes much longer for them to catch up to native speakers in academic language skills (Baker 1988). Similarly, we may often see children on the playground who appear to speak English with no problem. Yet when they are in a classroom situation, they just don't seem to grasp the concepts. Many people fail to realize that there are different levels of language proficiency. Actually, they still needed time and assistance to develop their academic English skills (Cummins 1984).

Research has already been done in the area of code switching or native language interference on the target language. There is considerable controversy over the definition of interference. Dulay (1982) defines interference as the automatic transfer, due to habit, of the surface structure of the first language onto the surface of the target language. Lott (1983) defines interference as "errors in the learner's use of the foreign language that can be traced back to the mother tongue". For example, interferences may be seen in the usage of the past tense, articles or the repeated pronoun. Ellis (1997) refers to interference as "transfer", which he says is "the influence that the learner's L1 exerts over the acquisition of an L2". In learning a target language, learners construct their own interim rules with the use of their L1 knowledge (Selinker 1972), but only when they believe it will help them in the learning task or when they have become sufficiently proficient in the L2 for transfer to be possible. The reason for the switching behavior presented by Crystal (1987) is the alteration that occurs when the speaker wishes to convey his/her attitude to the listener. Where monolingual speakers can communicate these attitudes by means of variation in the level of formality in their speech, bilingual speakers can convey the same by code switching.

Professionals in second language acquisition have become increasingly aware of the role the mother tongue plays in the EFL classroom. Nunan and Lamb (1996), for example, contend that EFL teachers working with monolingual students at lower levels of English proficiency find prohibition of the mother tongue to be practically impossible. Dornnyei and Kormos (1998) find that the L1 is used by L2 learners as a communication strategy to compensate for deficiencies in the target language. Auerbuch (1993) also acknowledges the positive role of the mother tongue in the classroom.

\section{Research Methodology}

Present research study has focused on teaching and learning process with the aid of L1 in communicating effectively L2 in EFL classrooms. However, no broad generalizations have been made rather the researcher has 
focused mainly upon:

1. The spoken aspect of L2 along with L1 in integrated skills classes

2. Proper use of vocabulary while communicating at intermediate level

3. The age group (between $15-26$ years)

The researcher has selected to analyze the research topic from the aspects of integrated skills as taught at King Abdul Aziz University (KAAU), Jeddah, Saudi Arabia to the learners of English language for the development of the topic. As analysis helps in thoroughly examining the topic from all dimensions, the researcher looks upon all the aspects of the research topic to discover how use of bilingualism expedites teaching and learning process in EFL classes.

The population comprises a total number of 150 students from KAAU (King Abdul Aziz University) at Certificate level and 25 teachers who were teaching these students. Although no studies have been located which aim to discover the contribution of the use of bilingualism in foreign language learning, there have been several studies which are pertinent in either content or method, and they will be outlined and commented on here. The most common methods used to investigate the relationship of L1 with L2, are the observation of teachers' regular lessons combined with semi-structured interviews. All of the studies outlined in the previous paragraphs used a combination of interviews and classroom observation since their primary aim was to discover links between $\mathrm{L} 1$ and L2.

The intention of this study was to find out whether the use of bilingualism is a teaching aid in teaching and learning L2 and L1 does facilitate the learners. The tools that were used comprised semi-structured interviews, questionnaires and classroom observations. There were some general concerns over the level of comprehension and proficiency among the respondents. So the questionnaire was designed and arranged in such a manner which would require the respondents to do as little reading as possible. The questions were always read out to the respondents by the researcher himself or by the other trained research fellows. They had been briefed to be aware of situations where the respondents needed extra assistance.

\subsection{Participants}

A total of 150 students who were selected randomly participated in this activity and 25 teachers gave their opinions while responding to the questionnaire. The teachers selected for the present study were from the immediate milieu and had been teaching the language skills for 0-30 years. Thus both newly inducted and experienced language teachers were included in this research.

\subsection{Classroom Observation}

Five teachers, who were teaching different language skills i.e. listening, speaking, reading and writing, were selected for classroom observation purpose. This proved quite helpful in finding out that teachers using different language skills had to employ L1 while teaching EFL. It was recorded then, how frequently and on what occasions L1 was used by the teachers and when by the students (see table-1). In order to obtain a more authentic and solid classroom data, the teachers and the students both were not made aware of the observation, or else it would have been nearly impossible to record their natural reactions. These classroom observations were about 50 minutes' duration.

\subsection{Semi-structured Interviews}

Second technique employed was to conduct semi-structured interviews of the five teachers whose classes were observed. The purpose of this was to find the reasons why they had to switch to mother-tongue (L1) and preferred using it over English. These teachers, more or less, came up with almost the same kinds of reasons for justifying their use of L1 in an EFL class. The interviews of these various teachers were recorded and interpreted as well.

\subsection{Questionnaires}

The third method employed to collect the relevant data for the authenticity of the research was to distribute questionnaires. There were two different kinds of questionnaires. One was given to the teachers and the other was given to the students. These questionnaires were designed to check and evaluate the attitudes and responses of both the learners and the teachers. The questionnaire given to teachers was aimed at discovering their practice, of using bilingualism in the classroom, the need which presses them to use mother-tongue (L1) and lastly, their response as to what extent the use of mother-tongue (L1) was helpful in their teaching methods. Its purpose was also to get an idea how far teachers are conscious of or dependent on the use of bilingualism in their teaching learning methods. This technique helped a lot, especially to substantiate data with observation. In addition, it 
helped the researcher to get a firsthand knowledge of teachers' awareness of this most serious subject. The second questionnaire which was given to the students proved quite helpful and effective in many different ways. Firstly, it helped to know students' reaction to the use of bilingualism in the class. Then it aimed to testify teachers' data. And finally its purpose determined the use of bilingualism in the improvement of their language skills in L2 especially those areas in which they felt the use of bilingualism was effective. Thus, questionnaires to students and teachers proved quite effective in gathering the data to analyze and evaluate the results and lastly, to the correctness of the hypothesis.

\section{Discussion on Classroom Observation}

The table shows that the number of occasions on which L1 was used in five 50 minutes classes for different purposes. The table displays clearly that all five teachers used L1 in a variety of situations on different occasions (see table 1).

Table 1. (Classroom Observation Result)

\begin{tabular}{llllllll}
\hline $\begin{array}{l}\text { Sr. } \\
\text { No }\end{array}$ & Occasions on which L1 was used & T1 & T2 & T3 & T4 & T5 & Total \\
\hline 1. & Giving Instructions & 3 & 2 & 2 & 3 & 2 & $\mathbf{1 2}$ \\
\hline 2. & Defining New Vocabulary Items & 2 & 1 & 3 & 2 & 2 & $\mathbf{1 0}$ \\
\hline 3. & Explaining Idioms and Proverbs & 1 & 1 & 0 & 2 & 1 & $\mathbf{5}$ \\
\hline 4. & Explaining Colloquial Expressions & 2 & 2 & 1 & 3 & 2 & $\mathbf{1 0}$ \\
\hline 5. & Explaining Prepositional Phrases & 1 & 3 & 1 & 2 & 1 & $\mathbf{8}$ \\
\hline 6. & Explaining Slang and Taboo Words & 2 & 3 & 4 & 1 & 1 & $\mathbf{1 1}$ \\
\hline 7. & Explaining Grammatical Rules & 3 & 2 & 3 & 2 & 1 & $\mathbf{1 1}$ \\
\hline 8. & Explaining Complex Ideas & 1 & 1 & 0 & 1 & 1 & $\mathbf{4}$ \\
\hline 9. & Creating Fun in Language Class & 3 & 3 & 4 & 1 & 0 & $\mathbf{1 1}$ \\
\hline 10. & Giving Suggestions to Learn Effectively & 2 & 1 & 1 & 2 & 1 & $\mathbf{7}$ \\
\hline & Total & 20 & 19 & 19 & 19 & 12 & $\mathbf{8 9}$ \\
\hline
\end{tabular}

All this appeared to be natural as claimed by the advocates of use of bilingualism in EFL context that it aids only when it is used judiciously. Thus the use of L1 by the teachers was according to the claims made by the researcher himself and testified to the propositions. To him, only English may lead to disturbance for the language activity. Same is the case with all of the abovementioned teachers, they first attempted to explain the words, grammatical points and meanings of complex ideas in English but resorted to Arabic when the teachers felt English instructions failed to work. Sometimes, it was the demand of the learners themselves that difficult and complex points be explained in L1 e.g. "tit for tat", examples for use of conditionals, etc. This situation is unavoidable for the teacher.

There is a general trend in Saudi Arabia that most of the local and foreign teachers, who had either Arabic or other language, would extensively use Arabic. Both students and teachers were at ease using students' L1 and no one wonders or feels disturbed in L1 use. First teacher, for example, used L1 most frequently. He used L1 20 times. He has been teaching English for more than sixteen years. He holds a $\mathrm{PhD}$ degree and the vast experience of teaching Saudi students. He had been in Saudi Arabia for more than ten years and was quite proficient in Arabic language. Although he used L1 (Arabic) more frequently than other teachers but he was well aware of the danger of unnecessary and inappropriate use of L1. So the fair and judicious use of L1 is advisable. Likewise, rest of four teachers also used Arabic whenever and wherever they felt its need.

Non Arab EFL teachers mostly fall back to the use of bilingual dictionary or the teacher usually depends on that learner who is good at comprehension. This learner facilitates the teacher by explaining new vocabulary items in $\mathrm{L} 1$ to the other learners. This technique proved to be fruitful and less time consuming. For example, excited, pollution, passion, monster etc. were explained in Arabic or the learners used bilingual dictionary to find the exact meaning. If proverbs and idioms are not explained in L1, these would create entirely a different idea in the minds of EFL learners. Consequently, the teachers have to resort to the use of L1. For example, during classroom observation, it was raining outside and the teacher used the idiom while teaching present continuous, "it is raining cats and dogs" but the learners failed to understand this idiom. When the teacher explained it using L1, they got it at once. At this occasion, the teacher explained some more proverbs using L1 e.g. "a stitch in time saves nine", "there are many a slip between a cup and a lip" etc. As far as colloquial expressions are concerned, it is very difficult for the EFL learners at intermediate level here to comprehend these expressions e.g. "shall I 
make you a cup of tea?" or "he is married with three children" (he marries not woman but three children as perceived by the learners) or "the cow is milking" or "the house is building" the teacher used these expressions and asked the learners to tell the meanings. They came up with interesting meanings. They explained the first expression as "shall I cook you and make you a cup of tea" with a funny translation. Later on, the teacher had to explain all these expressions in L1. This way, they found them easy and retained them for a long time. Prepositional phrases are also very confusing for the EFL learners. The teacher used L1 to explain the meanings of "break down", "bring up", "put up with" etc. Slangs and taboo words are strange to the learners. The teacher gave the examples of "fat", "handicapped", "black" etc. He told the learners in Arabic giving them some equivalents. Then they got the sense and meanings of these words. Certain grammatical structures are also difficult to understand for Arab EFL learners. For example, "I go" and "I am going" are taken as the same by the learners as these structures have no equivalents in Arabic. It is difficult for them to distinguish between present indefinite and continuous. They identify them from the situation or the continuous does exit at the back of the minds of the learners. They use the Arabic terminology "(moustamir (مستمر)" for the continuous. Similarly, while teaching use of "let" the teacher used the Arabic word "(da'ana (دعنا)", and for teaching conditionals he used "(lao kun to لوكنت (يستطيع (Arabic) and for the use of "can" he used Arabic equivalent "(youstateeh absence of helping verb in Arabic also poses problem for the learners. For example, "My name is Muhammad" (اسمى محمد) is usually produced by the Arab learners of English as "My name Muhammad". Actually, it happens because of interference of L1 and the teachers overcome this problem by using L1 as well. The teacher also resorted to Arabic while explaining some difficult vocabulary e.g. "monster city", blended family, extended family, nuclear family, single parent, one check family, double check family, stay at home husband etc. There is general trend of using double subject in Arabic which usually lurks into English by Arabs e.g. Ahmad ho wa talib "احمد هو طالب جيد" (Ahmad he is a student good). Actually he wanted to say "Ahmad is a good student" but not "Ahmad he is a student good" as "Ahmad" and "he" can't be used in a sentence together and "adjective" after "noun" but this arrangement is a correct structure in Arabic language. Moreover, another teacher told during an informal discussion that almost every day, he starts his class with little fun in L1. It brings back the learners to the class and removes boredom and motivates them to learn a new language. Before or after the class, he gives suggestions in L1 how to improve L2, he told. One more teacher shared the same kind of experience. He told that he also imparts instructions in L1 about how to attempt question paper and how to behave in the examination room; or sometimes if role play or when speaking activities are introduced in EFL, learners are instructed sometimes in L1 as it is less time consuming and more effective.

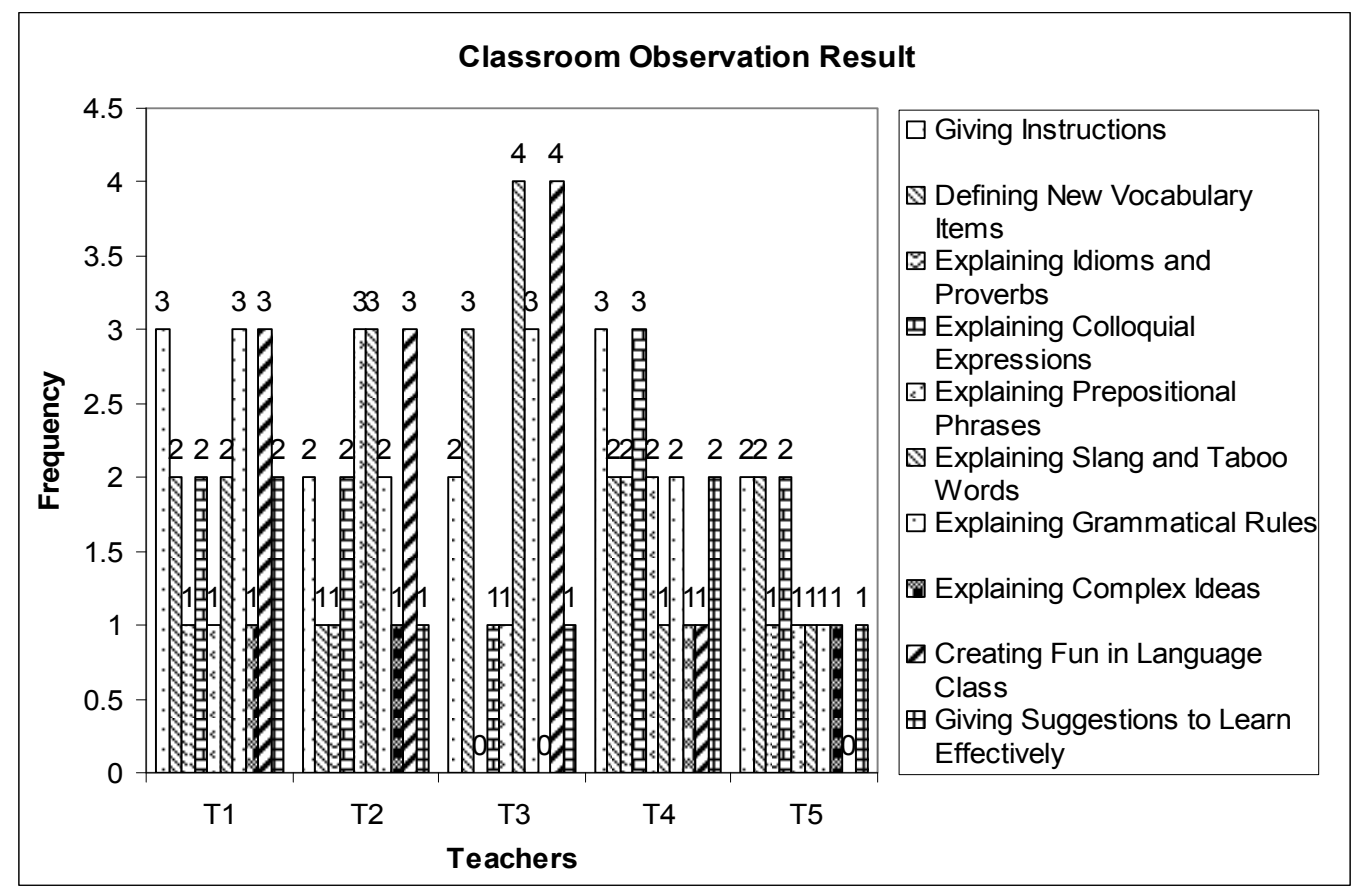

Figure 1. (shows frequency of L1 Use) 


\section{Discussion on Teachers' Responses}

An overwhelming majority ( $86 \%$ ) of teachers confirmed the proposition that bilingualism is helpful as a teaching aid in the EFL classroom. Only a small number of teachers refuted the proposition who could most probably be the inexperienced or less qualified teachers. Need of bilingualism appears to be more emphatic. That is why percentage of disagreement is so low. The reason is that the foundation of English in KSA in general is very poor English is taught from $6^{\text {th }}$ grade onwards and not with much sincerity especially at school level as it was revealed by the teachers during informal discussion with them. Therefore, the teachers at the universities have to start from the scratch hence bilingualism becomes indispensable in EFL classes.

In response to the statement, "the best way to learn L2 is through communicative approach", the responses gathered from the respondents were $40 \%$ in favour and $60 \%$ against this statement. The communicative approach in learning L2 emphasizes on exclusion of L1 completely. This approach is not fully endorsed by EFL teachers and moreover is not accepted by the EFL learners. Thus students as well as teachers find it hard to learn L2 more competently and less painfully considering communicative approach as the best at intermediate level in EFL context. Therefore, the teachers at KAAU $(60 \%)$ disregarded the statement that the best way to learn L2 is through communicative approach. So it confirms the reliance on the use of bilingualism in class.

In response to the statement "students retain L2 vocabulary for a long time with the help of bilingualism", the data (50\% in favour) corresponds again to the basic assumptions of the present study. This means that without the use and assistance of L1, it is difficult to teach L2 more accurately. These results show that the respondents (50\%) may have misconceptions about bilingualism when and how it should be used in EFL classrooms; that is why they are unaware of use of bilingualism.

In response to the statement "bilingualism as a teaching aid means the fair and judicious use of L1 in teaching and learning a foreign language", $90 \%$ of the teachers strongly agreed to this proposition. This data shows that bilingualism does not mean the exclusive use of L1 in EFL classrooms rather it means the balanced, fair and judicious use of L1 in EFL classroom. This would make it more facilitating and helpful to learn L2 in a friendly environment.

The proposition presented is that "bilingualism makes instruction easier". $80 \%$ of the teachers agreed to this proposition. This overwhelming majority of teachers endorsed that only through bilingualism or use of L1, L2 can be taught effectively and efficiently. The data appeared in this table is quite natural.

In response to the statement "cultural associations favour bilingualism", $84 \%$ of the teachers gave positive response i.e. in its support as it is very important for the learners simultaneously to learn L2 and maintain L1. The data findings strongly support bilingualism without which it will not be very easy for the learners to learn L2 and to maintain L1. Language is a product of particular culture. Without having assimilated cultural associations that are attached with the linguistic competence and fluency is far more difficult to be achieved.

Language is culture and vice-versa. It does not exist in a vacuum. It is the vehicle of culture. At times, languages fail to communicate because of cultural gap. These are the moments when parallels of cultural associations are drawn to establish a rapport. These cultural associations help a great deal to bilingualism in learning L2. The results of the question are quite in agreement with this view.

The next question asked from the teachers was "Do you think a learner will grasp L2 better if the teacher uses only the target language?" $85 \%$ of the teachers disagreed to the monolingual approach responding to this question and opted "No" which means that they denied the viability of this question. Results show that the students' learning capabilities and performance shall comparatively be less and it would increase and accelerate the process of learning L2 if L1 is used in EFL classes. Thus the communicative approach in spite of its advantages is faulty and less productive than the use of bilingualism.

$90 \%$ of the teachers hold this opinion that use of bilingualism brings practical advantages for the learners. This refers to famous thesis in ELT that language is a living phenomenon. Therefore, the true expertise uses the practical vocabulary in a living language, not the use of archaic or obsolete words which the literature of the language carries. Thus the learners with the help of L1 are able to comprehend and use the language which is needed most in practical life. Therefore, the result tallies with major theories in English language teaching.

The respondents seem to have at the back of their mind the modern trend that bilinguals have an edge over the monolinguals even if they are the native English teachers. This is true of every country, be it Arabia, England, Russia, china or late Chinese and Japanese have also realized the importance of bi/multilingualism and they have started intensive teaching programmes of other languages. 


\section{Discussion on Students' Responses}

The question about the usefulness of bilingualism asked from the teachers was also asked from the students. $97.9 \%$ of the students responded to "yes" option whereas $2.1 \%$ of the students selected "no" option. Overwhelming majority confirmed that bilingualism is helpful as a teaching aid in EFL classroom.

The data shows that bilingualism is not only liked but is needed most in EFL classrooms even for those students who had already studied the target language for some years. At times it is argued by the linguists that the use of L1 may be advisable at elementary level but not at advanced or intermediate level.

The argument appears to be logical but the reality is that the students who are the major stake holders are indeed more interested in the use of L1 by their teachers. Therefore the teachers have to cater for their needs. A cursory glance at the data shows that a vast majority (97.9\%) desired use of bilingualism in EFL classroom.

$79 \%$ of the respondents agreed and responded in a positive manner towards the question "Is bilingualism less time consuming in EFL classroom?" It seems quite logical because it is a proven fact when the teacher used L1 during class to explain idioms and phrases, difficult words to explain according to the situation. So the use of bilingualism while explaining idioms and phrases proved to be economical in terms of time for the learners and the teachers. On the contrary, the teacher might not succeed using only English approach. The data again refers to the established opinion of most of the language teachers that bilingualism is unavoidable in a language classroom. Without use of bilingualism, it will not only be more time consuming for both the teachers and the students to teach and learn but also leads to communication gap which may rather lead to wrong, misappropriate and incorrect language learning. However, it takes a long time to slough off wrong learning and sometimes students carry it with them throughout their lives. Thus the whole process and exercise of learning a language becomes futile.

79.7\% students marked "yes" option in response to the question "With whom are you comfortable in the classroom? with a monolingual teacher or with a bilingual teacher?" The data shows that almost all the students showed their liking for "bilingual teacher" because bilingual teacher facilitates the learners with the help of L1. The learners feel that they can ask "why" or "how" questions from a bilingual teacher and share a concern whether it be illness or social need or a comment in L1. If the teacher is bilingual, the students will be more prone to learning owing to feeling confident, safe and heard in the English language environment. The relationship between the learner and the teacher is crucial and by validating the student via recognizing his/her language and communicating with the student in L1, a relationship of mutual respect is created and student may feel the power of being able to use both languages as a tool of communication. High percentage of respondents towards bilingual teacher proves that bilingualism is useful for more comfortable learning environment where everyone's goal will be accomplished; the teacher can teach to a student that is open to learning and English proficiency is attained.

The question "How important is for you to know English?" was categorized with four different options i.e. "very important", "important", "not important", "not at all important". The results display that $24 \%$ selected "very important option, $69.1 \%$ opted "important". Only 4.8\% selected "not important". Moreover, $2.1 \%$ of the respondents responded to the last option "not at all important". The data shows the level of interest that the students have about the use of English in their lives. Students in Saudi Arabia wish to learn English even if it is not used in their daily lives. This is also because English has acquired the status of lingua franca of the world. With the advent of globalization, everybody envies the use of English, be it one's home, or workplace, or entertainment area or conferences etc where English is used extensively. Thus it is true about Saudi students "to know and learn English has become a world craze".

The question "How often L1 should be used in the classroom?" has also been categorized with four different options "a lot", "sometimes", "a little", "never". The results display that $31.5 \%$ selected the option "a lot", $37 \%$ selected "sometimes", $22.6 \%$ opted "a little". However, a small number of students with $8.9 \%$ selected "never". This data points out to another aspect of the bilingualism problem that the use of L1 is necessary, but it should not be used constantly because this would also hamper the process of language learning to a great extent. The learners may become too relaxed, may not be very actively involved in it or lose interest because of too much reliance on the use of L1. Thus as has previously been pointed out, the fair and judicious use of L1 helps but frequent and persistent use leads to the end of learning a foreign language.

\section{Discussion on Teachers' Interviews}

After classroom observation, the teachers whose classes had been observed were interviewed about their occasional use of L1 in the classroom and how they viewed the common criticism that using L1 reduces the 
students' exposure to L2. The important point is that the teachers were not informed in advance about the classroom observation. It helped the researcher to collect data for his research in an objective manner. Moreover, the authenticity and validity of research was ensured through this method. Students and teachers were not conscious of their use of L1 in the classroom. Almost all the teachers emphatically say that bilingualism is helpful as a teaching aid in EFL classes. The teachers agreed that overall comprehension of the language at the initial stages is necessary and this is one area which cannot be facilitated without the aid of L1. They would not suggest the constant use of L1 because it would hamper linguistic competence and fluency. This would lead to practical advantages in learning L2 and results in L2 competence. Concepts of learners formed in L1and explained by the teacher are not to be completely washed out or not completely locked. If teachers are teaching in such circumstances, bilingualism facilitates their conceptual learning. They believe that the abstract words compel teacher and learners to employ bilingualism. Majority of teachers who were interviewed assert that bilingualism is a bridge between the teacher and the learners. Moreover, they say that it is, for sure, motivates and facilitates learners. Overall the teachers were in favour of bilingualism but some of them emphasized at different places along with some of the reservations as far as the competence of language learners is concerned. This is exactly what researchers and scholars in the field of bilingualism claim and assert.

The general idea drawn from these interviews is that bilingualism is essential and helpful when there is no other option left for the teacher to define or explain the meanings and connotations of a word or a phrase. They are convinced that use of bilingualism in EFL classes proves fruitful for a productive teaching learning process for the language learners. They claim it to be their personal experience.

\section{Conclusion and Recommendations}

Present study shows that the use of bilingualism has an important role in teaching and learning L2 at intermediate level. The use of bilingualism has been employed as a teaching technique in EFL classes. The teachers who participated in the present research study indicated that the translation of abstract words, complex ideas and phrases in L1 is a facility to learn a foreign language. Without the aid of L1, learners would be left unguided at an early stage of their learning experience. This study also reveals that in EFL classes, use of bilingualism has played only a supportive role hence the medium of instruction remains, no doubt, English only. Moreover, the use of bilingualism does not decrease the motivation level of students' learning English. Use of bilingualism in EFL classes does not reduce students' exposure and capacity to communicate well in L2 rather it substantiates English language learning and it is an immense source of motivation for the EFL learners. It has no adverse effect on learning as long as it is used with considerable restraint.

In order to aid and facilitate the language learning process with the help of first language, there are certain recommendations for the teachers, which have been /can be drawn from the current research study.

1. The first recommendation for the teachers is that they should maintain and improve the motivation level of the students. The students feel more motivated when they learn in a familiar environment. If the use of first language is strictly prohibited, the students would feel alienated and apprehensive while in a familiar environment, they feel more communicative with the teachers. It is, therefore, stressed that the teachers may not only be allowed but they need to prefer bilingualism while explaining difficult words, phrases and complex structures of the target language. The motivation level can thus be achieved, maintained and improved enormously.

2. The second recommendation is that the use of bilingualism must be moderate and judicious. It is important that the major medium of instruction must be English. The students ought to be made familiar with the target language with its pronunciation, structural, socio-cultural and semantic contents to learn clearly and appropriately different contours of the target language. However, the first language (L1) is to be used for different purposes. It can be utilized when difficult words, proverbs and sayings need to be explained to the students. L1 can also be employed while explaining difficult and complex ideas are being conveyed to the students. To explain complex grammatical structures, it ought to be resorted to. In explaining difficult phonological points, L1 sounds can be produced, so that the students can grasp the sounds with constructive and comparative techniques. However, in all these, the use of L1 should be appropriate and judicious. As stated earlier, the students are to be made familiar with the various contents of the target language L2 English. In the current study, majority of the students and the teachers have suggested that 20-30 percent of the total time should be allocated for the use of L1. But the teachers have to take decision in allocating the time to cope with the needs of the learners.

3. The third recommendation is that in foreign language learning/teaching, it has often been observed that the loss of social and cultural identity of the learners results in a monolingual class. This is not a 
much-favored condition. The important thing is that some of the teachers and students think that learning the target language involves the absorption of the social and cultural context. It need not be aimed at. The learners must create a balanced and mature attitude, that they are learning the language only; they are not changing their identity. They have to pick the sounds, structures and meanings of the target language, but not the culture. This situation can be dealt with a proper fashion, if students are being familiarized with the use of their mother tongue/L1 especially in the third world countries, under the compelling forces of globalization, the communities are losing their native culture along with the language, which results in the death and loss of such a diversified and rich heritage of world cultures.

4. The fourth recommendation is that the teacher should emphasize the similarities and contrasts of both the languages thereby making the learners more familiar with the grammatical components of L1 and L2. It would be helpful for the learners to grasp, comprehend and master various language items in their language learning process. As a result, learners very quickly explore their mistakes that occur advertently or inadvertently. Therefore, curriculum needs to be shaped in such a manner where teacher can effectively take up such a deal.

5. The fifth recommendation would be that the language learning process would become more purposeful and meaningful. In contrast to language analysis, language-learning experience is the use of target language for real and immediate communicative goals. However, if the teachers resort to English only, for those learners who are accustomed to being taught exclusively in their mother tongue may at first be uncomfortable if their teachers speak to them in English only, expecting them not only to understand but perhaps even to respond. Thus, it needs to be supplemented more at early stages.

6. Sixthly, the use of bilingualism wherever required, may prove to be an important tool for the learners to understand L2 with ease, hence to assess their own learning progress. As a matter of fact, the usefulness of self-assessment for learning purposes seems to be widely accepted although it is far less common and many actively resist its implementation. However, it is an important and effective technique to know one's own worth through these techniques. Thus, the use of bilingualism is recommended for language learning process.

7. Lastly, in classes where all learners share the same L1, teachers need to use a range of options to encourage learners to use L2 as much as possible. The following range of options is based on the idea that there are several reasons why the learners prefer the use of bilingualism most frequently while learning L2. These reasons include low proficiency in L2, the least eagerness to use L2 while interacting with teacher in performing the class activities, shyness in using L2 or simply a lack of interest in learning L2.

Here are some of the remedial measures dealing with these obstacles (Recommendation 7) in L2 use.

a. Choose the teaching materials well suited to the needs of the learners for their proficiency.

b. Prepare learners for tasks with the help of warm-up activities and skills needed.

c. Use systematic and graded tasks to mark learners' progress step by step to bring them up to the required level.

d. Motivate learners to pretend to be English speakers.

e. Make L2 an unavoidable part of the task. Retelling activities, strip stories, completion activities, and role plays all require the use of $\mathrm{L} 2$.

f. Repeat language games and classroom activities for learners' better comprehension to ease and facilitate the learning process.

g. Inform learners of the significance of language-specific activities in class. This will help learners achieve their learning objectives.

h. Discuss with learners the value of using L2 in class.

i. Discuss the reasons why learners avoid using L2 and provide them with appropriate remedy so that they should overcome their aforesaid shortcoming in the use of $\mathrm{L} 2$.

j. Set up a monitoring system to motivate learners to use L2 frequently. In group work speaking tasks this can involve giving one learner in each group the role of reminding others to use L2.

k. Use learners-friendly and popular situational activities. Learners can choose their own groups, the teacher can stay out of the groups allowing learners to prepare well for the situation, don't use such 
situations that embarrass learners, and choose easy and interesting tasks.

If encouraging L2 use is a problem, several of these different solutions may need to be used. These solutions cover a range of affective, cognitive, and resource approaches and thus can be seen as complementary rather than as alternatives.

In some countries, English and L1 are in competition with each other and the use of English increases at the expense of L1. Teachers need to show respect for the learners' L1 and need to avoid doing things that make L1 seem inferior to English. At the same time, it is the English teacher's job to help learners develop their proficiency in English. Thus, a balanced approach is needed which sees a role for L1 but also recognizes the importance of maximizing L2 use in the classroom.

In a nutshell, in order to recapitulate, it is argued that the research shows that limited, moderate and judicious use of L1 in Saudi Arabia, and in the world in general, does not reduce students' exposure to L2, but rather can assist in the teaching and learning process. It is hoped that these findings and recommendations will help make more people acknowledge the role of bilingualism in the foreign language classroom and stimulate further studies and insights in this area.

\section{References}

Albert, M. L., \& Obler, L. K. (1978). The Bilingual Brain: Neuropsychological and Neurolinguistic Aspects of Bilingualism. New York: Academic Press.

Auerbach, E. R. (1993). Re-examining English only in the ESL classroom. TESOL Quarterly, 27(1), 9-32. http://dx.doi.org/10.2307/3586949

Baker, C. (1988). Key Issues in Bilingualism and Bilingual Education. Multilingual Matters, Avons.

Beligan, A., Clyne, M., \& Lotherington, H. (1999). Growing up with English plus. Melbourne: Language Australia.

Collier, V. P. (1995). Promoting academic success for ESL students: Understanding second language acquisition for school. NJTESOL-Bilingual Educators.

Crystal, D. (1987). The Cambridge encyclopedia of language. Cambridge: Cambridge University Press.

Cummins, J. (1984). Bilingualism and special education: issues in assessment and pedagogy. Clevedon Multilingual Matters.

Cummins, J., \& Swain, M. (1986). Bilingualism in education. Essex: Longman.

Dornyei, Z., \& Kormos, J. (1998). Problem-solving mechanisms in L2 communication: A psycholinguistic perspective. Studies in Second Language Acquisition, 20(3), 349-385. http://dx.doi.org/10.1017/S0272263198003039

Dulay, H. C., Burt, M. K., \& Krashen, S. (1982). Language Two. New York: Oxford University Press.

Ellis, R. (1997). The Study of Second Language Acquisition. Oxford: Oxford University Press.

Hakuta, K. (1986). Mirror of language: The debate on bilingualism. Basic Books.

Hamers, J. F., \& Blanc, M. H. A. (2000). Bilinguality and bilingualism (2nd edition). Cambridge, Cambridge University Press.

Krashen, S. (1981). Second language acquisition and second language learning. Oxford: Pergamon Press.

Lotherington, H. (2000). What's bilingual education all about? A guide to language learning in today's school. Melbourne: Language Australia.

Lott, D. (1983). Analysing and counteracting interference errors. ELT Journal, 37(3), 256-261. http://dx.doi.org/10.1093/elt/37.3.256

Nunan, D., \& Lamb, C. (1996). The self-directed teacher. Cambridge: Cambridge University Press.

Schweers, C. (1999). Using L1 in the L2 classroom. English Teaching Forum, 37(2), 6-9.

Selinker, L. (1972). Interlanguage. International Review of Applied Linguistics, 10, 201-231. http://dx.doi.org/10.1515/iral.1972.10.1-4.209

Skutnabb-Kangas, T. (1981). Bilingualism or not: the education of minorities. Clevedon, Multilingual Matters.

Tang, J. (2002). Using L1 in the English classroom. English Teaching Forum, 40(1), 36-43. 


\section{Appendix}

\section{A. Questionnaire (for teachers only)}

1. Is use of bilingualism helpful as a teaching aid in EFL classroom?
a. Yes
b. No

Yes: $86 \%$ No: $14 \%$

2. Is the best way to learn English language only through communicative approach?
a. Yes
b. No

Yes: $40 \%$

No: $60 \%$

3. Do students retain L2 vocabulary for a long time with the help of bilingualism?
a. Yes
b. No

Yes: $50 \% \quad$ No: $50 \%$

4. Does bilingualism mean the fair and judicious use of $\mathrm{L1}$ in teaching and learning a foreign language?
a. Yes
b. No

Yes: $91 \%$

No: $09 \%$

5. Does bilingualism make instruction easier for the teacher?
a. Yes
b. No

Yes: $88 \%$

No: $12 \%$

6. Do cultural associations favor bilingualism?
a. Yes
b. No

Yes: $84 \%$

No: $16 \%$

7. Does a learner grasp L2 better if s/he uses only the target language?
a. Yes
b. No

Yes: $15 \% \quad$ No: $85 \%$

8. Does use of bilingualism lead to practical advantages in learning L2?
a. Yes
b. No

Yes: $90 \%$ No: $10 \%$

\section{B. Questionnaire (for Students only)}

1. Is use of bilingualism helpful as a teaching aid in EFL classroom?
a. Yes
b. No

Yes: $97.9 \% \quad$ No: $2.1 \%$

2. Is use of bilingualism less time consuming in EFL classroom?
a. Yes
b. No

Yes: $79 \% \quad$ No: $21 \%$

3. With whom are you comfortable in the classroom?
a. Monolingual teacher
b. Bilingual teacher
Monolingual teacher:
$21.3 \%$
Bilingual teacher: $79.7 \%$

4. How often L1 should be used in the classroom?
a. a lot
b. sometimes
c. a little
d. never
a lot: $31.5 \%$
sometimes: $37 \%$
a little: $22.6 \%$
never: $8.9 \%$

5. How important is for you to know English?
a. Very important
b. important
c. not important
d. not at all important

very important: $24 \%$ important: $69.1 \%$ not important: $4.8 \%$ not at all important: $2.1 \%$ 